\title{
In Memory of Arthur Strong Wightman
}

Barry Simon, Coordinating Editor

Arthur Strong Wightman, the Thomas D. Jones Professor of Mathematical Physics at Princeton University and a founding father of modern mathematical physics, passed away on January 13, 2013, at the age of ninety. He was a key figure in the development of a rigorous mathematical physics that uses ideas of functional analysis and operator theory. His influence went far beyond his published research, which mainly focused on clarifying the compatibility of special relativity with quantum theory in the framework of quantum field theory.

Wightman was born on March 30, 1922, in Rochester, NY. He served in the US Navy after getting an undergraduate degree at Yale in 1942. After the end of the Second World War, he came to Princeton intending to work with Eugene Wigner, who was spending most of his time at Oak Ridge. So Arthur wrote his $1949 \mathrm{PhD}$ thesis "The moderation and absorption of negative pions in hydrogen" under John Wheeler.

Except for sabbaticals and other visits, he spent the remainder of his career in Princeton, initially in physics but eventually jointly in the two departments of mathematics and physics. His visits to Copenhagen in 1951-52 and 1956-57 and the interactions with Gunnar Källén and Lars Gårding in nearby Lund had a tremendous impact on him. He sometimes talked of his interactions there also with the previous generation, especially Wolfgang Pauli in Copenhagen and Marcel Riesz in Lund.

Gårding was a collaborator on parts of Wightman's most famous work, the development of what was called axiomatic field theory (and also on the classification of the representations of certain infinite-dimensional Heisenberg groups). The idea was that techniques of juggling the infinities of perturbation theoretic quantum field theory were

Barry Simon is the IBM Professor of Mathematics and Theoretical Physics at Caltech. His 1970 PhD thesis was supervised by Wightman. He and Wightman were colleagues on the Princeton faculty from 1969 to 1981. His email address is bsimon@ca7tech.edu.

DOI: http://dx.doi.org/10.1090/noti1219 remarkably successful but seemed to be mathematically shaky. Under these circumstances it was sensible to state precisely what one should mean by a relativistic quantum field. The result was a set of axioms, originally for vacuum expectations values in Wightman's 1956 paper and then in

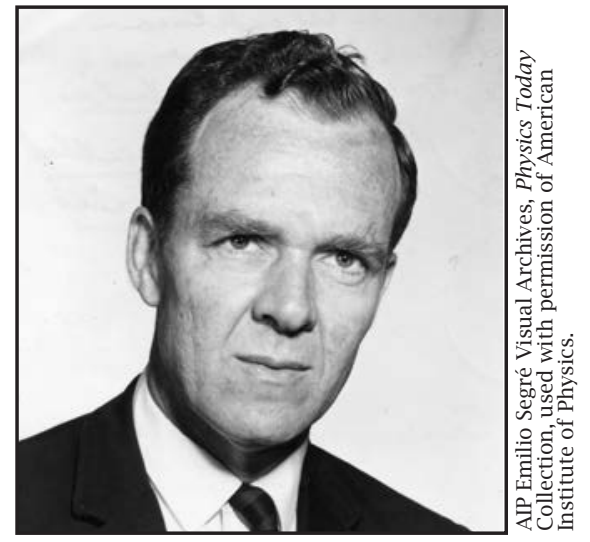

Arthur Wightman, circa 1960. a variant of Gårding and Wightman in terms of operator-valued distributions. It is of course no coincidence that this use of distribution theory to revolutionize how mathematicians think about quantum field theory took place in the same place where Lars Hörmander was using distribution theory to revolutionize PDEs.

The operator-valued distribution approach spread informally, and its success especially in the Haag-Ruelle scattering theory led to the 1964 publication of the Gårding-Wightman axioms and the celebrated book with Ray Streater, PCT, Spin and Statistics and All That (Princeton University Press, 1964).

Wightman's influence was magnified by an array of graduate students (see the list on the Math Genealogy website) and postdocs. His broad interests are illustrated by the fact that, while his most celebrated work is in axiomatic quantum field theory, he supervised PhD students in areas as wide as classical mechanics (Raphael de la Llave and Jerry Marsden), nonrelativistic quantum mechanics (John Dollard and Barry Simon), operator algebras (Huzihiro Araki and Robert Powers), Feynman diagrammatic perturbation theory (Vincent Rivasseau and Eugene Speer), statistical physics (Christian Gruber), and constructive quantum field theory (Arthur Jaffe and Oscar Lanford). 


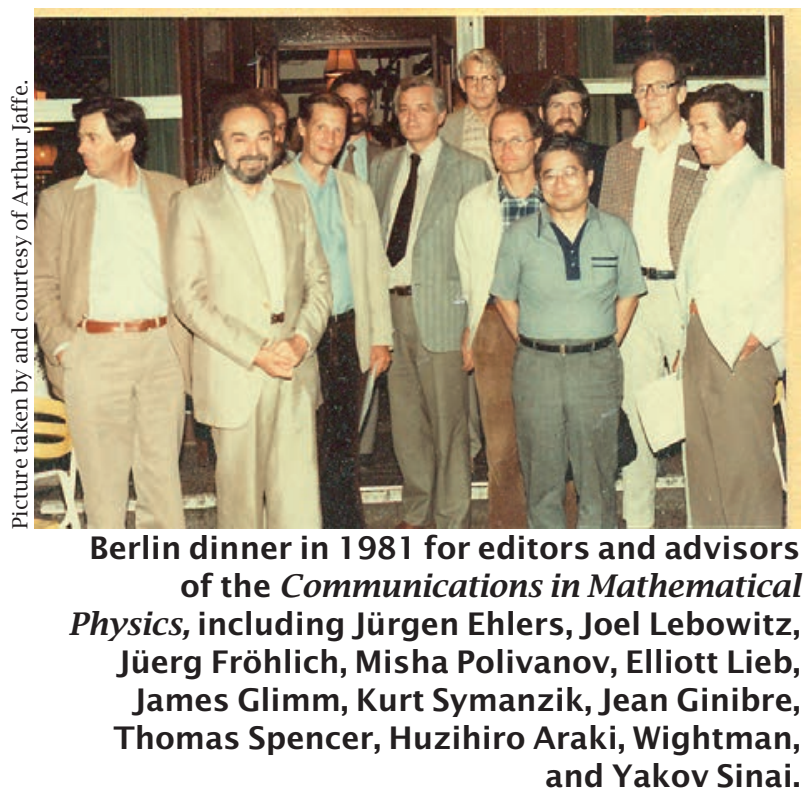

Arthur had impact outside Princeton, his research, and his students. He helped set up the program in mathematical physics at IHES and encouraged the founding of Communications in Mathematical Physics. In 1973 Giorgio Velo and Arthur Wightman began their series of productive summer schools in Erice. He served as an associate editor of Communications in Mathematical Physics, as well as editing book series for Benjamin and for Princeton Press. As a member of the board of Princeton Press, he was a key early supporter in getting the Einstein Papers project under way. Arthur was the editor of Wigner's complete works published by Springer.

Arthur married Anna-Greta Larsson. She and their daughter, Robin, died from cancer at a young age. Arthur's second wife of thirty-five years, Ludmilla Popova Wightman, and his stepson, Todor Todorov, survive him.

For his work Wightman received the 1969 Dannie Heinemann Prize for Mathematical Physics from the American Physical Society and American Institute of Physics, and the inaugural Henri Poincaré Prize from the International Association of Mathematical Physics in 1997. He was the 1976 AMS Gibbs Lecturer. He was a member of the National Academy of Sciences; Fellow of the Royal Society of Arts, London; Fellow of the American Academy of Art and Sciences; a Doctor of Science of the Swiss Federal Institute of Technology (1968); and Doctor Honoris Causa of Göttingen University (1987).

We have collected some reminiscences from a few of the many scientists whose lives were impacted by Wightman. Princeton has a website (https://www.princeton.edu/ physics/arthur-wightman/) with additional comments, and there is a charming blog post at quantumfrontiers.com/2013/03/13 remembering-arthur-wightman/from a former undergraduate advisee. The reader may also want to consult two articles that appeared in the IAMP News Bulletin: from January 2013 www . iamp. org/bu11etins/o1d-bu11etins/201301.pdf), an obituary by Arthur Jaffe and Barry Simon, and from April 2013 (www. iamp.org/bu7letins/oldbu11etins/201304.pdf), "Nine lessons of my teacher, Arthur Strong Wightman" by Arthur Jaffe.

\section{Jüerg Fröhlich}

In 1949 Arthur Strong Wightman got his PhD degree from Princeton for work entitled "The moderation and absorption of negative pions in hydrogen." Three years later, he co-authored a paper with Gian Carlo Wick and Eugene Wigner that bears the title "The intrinsic parity of elementary particles." In their seminal work the concept of a superselection rule was introduced. In the early fifties, in joint work with Lars Gårding, Arthur formulated the basic principles underlying local relativistic quantum field theory, and in the company of friends, colleagues, and students he then started to deduce physically relevant consequences from the so-called "Wightman axioms."

Arthur Wightman is not remembered for the work contained in his thesis. But he is and will be remembered for his studies of the fundamental principles underlying local relativistic quantum field theory and for having helped-and for having inspired his followers and students-to derive important results from those principles. The use of advanced mathematics was not an end in itself but was forced upon him and his peers because they wanted to understand relativistic quantum field theory, just as Born, Heisenberg, and Jordan did not consider the mathematics of infinite matrices to be an end in itself but a remedy in formulating and embellishing the new quantum mechanics.

Arthur Jaffe has called Wightman the "spiritual leader of (modern) mathematical physics," and he fears that "his death really marks the end of an era." I agree with the first statement, but am more optimistic than Jaffe concerning the second statement. We owe the twentieth-century revolutions in theoretical physics to people who were mathematical physicists in the very best sense of this term. In studying the deep problems of physics, they did not consider mathematics to be an end in itself but to be the natural tool for reading the Book of Nature-just as Arthur Wightman did thirty years later.

Jüerg Fröhlich is a professor emeritus at ETH Zürich. From 1974 till 1977 he was an assistant professor at Princeton and a mentee of Arthur Wightman. He frequently returned to Princeton for shorter or longer visits and always enjoyed the discussions with Wightman. His email address is juerg@phys.ethz.ch. 
The clouds obfuscating the basic laws of the microcosm during the days of the old quantum theory and the clouds that concealed the theoretical foundations of particle physics in the early fifties dispersed through the work of people who had an intimate and nontrivial relationship with mathematics and used mathematics in a pragmatic but quite professional way. There are thick clouds lying over some of the deepest mysteries of the physics of our time. Theorists in the tradition of people like Arthur Wightman who have a taste for qualitative reasoning, do not despise mathematics, and attempt to do more than just solve one technical problem after another are likely to play an important role in helping to dispel those clouds in the future.

In my formative years I was fortunate to be under the spell of Arthur Wightman and to be exposed to his way of approaching problems in theoretical physics. I have profited from his vision and his patience with inexperienced youngsters. His exemplary intellectual integrity and his extraordinary generosity towards colleagues and students may be considered to be his main legacy. I remember him gratefully.

\section{Francesco Guerra}

The first time I met Arthur S. Wightman was upon my arrival in Princeton in September 1970. I came from the University of Naples, where I had received my doctoral degree in 1964 . However, I already had a quite complete idea about the scientific and human personality of Arthur. In fact, my mentors in theoretical physics, Eduardo R. Caianiello and Gianfausto Dell'Antonio, visited Princeton many times, were well acquainted with Arthur, and were his personal friends. During the sixties I was involved in research on renormalization theory, in the study of some simple models, and in the development of analytic regularization in configuration space. Moreover, I studied axiomatic field theory and was deeply impressed by the mathematically rigorous and physically relevant constructive program put forward by Arthur in his 1964 Cargese lectures. Hence my firm decision to spend some time in Princeton.

I remember with deep gratitude and affection the daily contacts with Arthur. I was impressed by his generous sharing of ideas and knowledge, by his participation in the unavoidable difficulties, the encouragement, and the help in developing research topics. An essential part of Arthur's style

Francesco Guerra is a professor of theoretical physics at the University of Rome "La Sapienza." He was invited to Princeton by Arthur Wightman as a research associate in the physics department in 1970-72. His email address is francesco.guerra@roma1.infn.it.

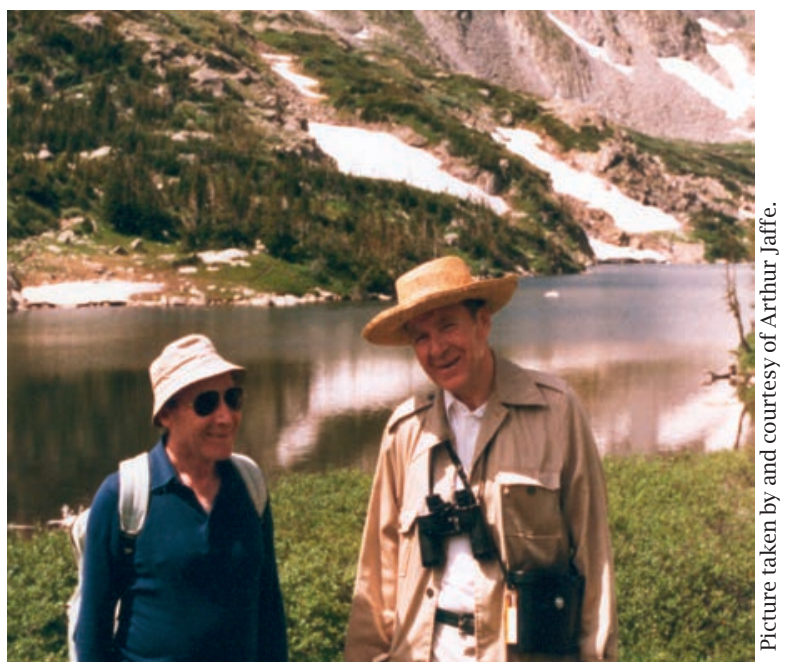

Wightman and Rudolph Haag at the Boulder meeting of the International Association of Mathematical Physics, 1983.

in personal relations was a typical use of irony and self-irony in their highest cultural meaning. I will give an example well fixed in my mind. At the beginning of 1972 I got some preliminary but quite strong results about the behavior of the vacuum in the infinite volume limit by using new methods of Euclidean quantum field theory recently developed by Edward Nelson. Quite naturally, I was hesitant to publish the results, because I was sure that much more could be easily obtained. One morning Arthur came to my office, asked about the status of the publication, and told me that I should hurry by giving the following image: "You are in the same situation as the young boy trying to stop the water from the dike by putting his small finger on the hole." It was good advice, promptly followed. In fact, Euclidean methods proved immediately to be very useful by producing a lot of new results in constructive quantum field theory. I was lucky to participate in the "flood" through a long and fruitful collaboration with Lon Rosen and Barry Simon, promoted by Arthur.

After leaving Princeton I was regularly in touch with Arthur through an enlightening correspondence.

The last time I saw him was during a visit to his clinic in 2008. The essential rich sprinkle of his mind was intact-in particular self-irony. He proudly showed us his last production: a wooden carriage train built for rehabilitation purposes.

Arthur will live in our minds and hearts forever.

Klaus Hepp is a professor emeritus of theoretical physics at the Swiss Federal Institute Zürich (ETHZ). His 1962 $\mathrm{PhD}$ thesis was supervised by Res Jost, a close friend of Wightman. He was at the Institute for Advanced Study in Princeton 1964-66, interacting with Wightman as much as possible. His email address is khepp@phys.ethz.ch. 


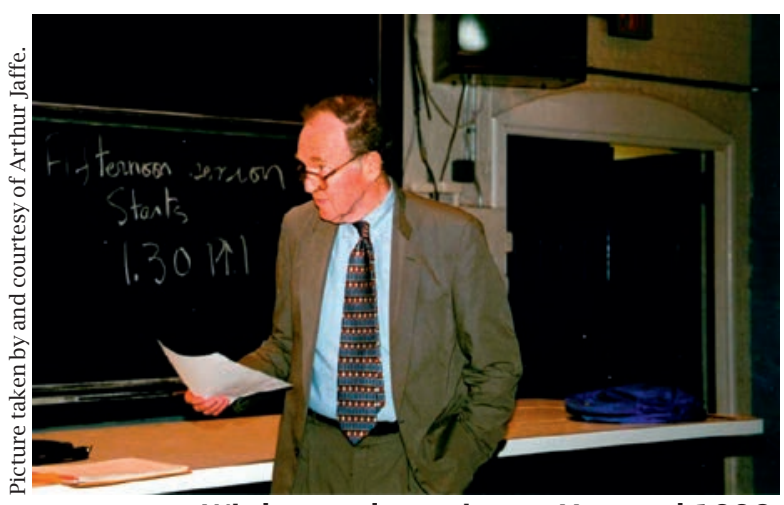

Wightman lecturing at Harvard 1998.

\section{Klaus Hерp}

Remembering Arthur Wightman is for me, as for many of us, a return to the best time of my life. I "met" Arthur frequently before I came to Princeton. As a graduate student in Zürich, Res Jost asked me to explain in the proseminar Arthur's famous paper "Quantum field theory in terms of vacuum expectation values." At that time I imagined Arthur to be a very old man with a grim face. Later I saw a photo of him taken at the Varenna Summer School 1958, sitting on the ground with a boyish smile. In my master's thesis at ETH I struggled with Arthur's synthesis of group theory with holomorphic functions of several complex variables to simplify the proof of the theorem of Hall and Wightman. Now Arthur became for me a great conductor.

In the winter 1963-64 I first met Arthur personally in Paris. I remember a wonderful dinner at Le Procope, to which Arthur and Res Jost had invited Arthur Jaffe and me. Although I was from 1964 to 1966 in Princeton at the Institute for Advanced Study, I spent more time in Arthur's office and in his lectures than anywhere else. I enjoyed the dialogue he had with the audience, his struggles to present deep results, and I had the great chance to fill some gaps in the proof of the Bogoliubov Parasiuk theorem on renormalization, which Arthur had pointed out.

The Hepp family (Marie-Claude and I) were frequently Anna-Greta and Arthur's guests at their home. There we got impregnated by the writings of Barth, Bellow, Heller, Pynchon, Roth, Wolfe, and many others unknown to us illiterate Europeans: we became immersed in the Anglo-Saxon world, and we loved America. Once we went with Arthur to the famous football game, where Princeton lost to Dartmouth at the end of an undefeated season. At the Wightman party to celebrate the expected victory, the wine was seasoned with sadness.

In later times my interests drifted towards neurobiology, and I no longer interacted so much with Arthur and his school. The last time I saw Arthur was at the Rutgers meeting in honor of Elliott
Lieb, watching the audience from a back seat and drifting slightly into his own world. I knew that I would never see him again, but I will never forget him.

\section{Arthur Jaffe}

First encounters not only shape our perceptions but can also influence one's destiny. Learning experimental physical chemistry as a Princeton undergraduate hardly prepared me for my eventual life's work. While realizing that I would not be happy following in my father's footsteps in medical research, Donald Spencer fortuitously encouraged my changing direction to study mathematics, and Charles Coulston Gillespie connected me with Clare College.

Only in Cambridge did I discover Arthur Wightman's wonderful papers. At the time I was struggling, with continual frustration, to learn mathematical physics. What a striking difference Arthur's clarity provided! Compared with papers where the physics ideas seemed to be hidden, intentionally or not, under layers of jargon, his were magic. Naturally I developed an intense desire to return to Princeton in spite of the temptation to remain in charming and stimulating Cambridge, England. Two years earlier a trajectory back there would have seemed unimaginable, but my longdistance exposure to Arthur Wightman made my motto "Princeton or bust."

The focal point for Princeton graduate students interested in physics and mathematics was the (Old) Fine Hall Common Room. Everyone needed to pass that space to go between the two departments, to read notices of seminars thumbtacked to the cork bulletin board in the hallway, to access the stairs to the famous library on the floor above, to ask a mathematical question, or to visit the local mailroom. One September afternoon I happened to be reading in a comfortable easy chair in the Common Room, opposite the door. Wightman was on leave at the IAS, and I had not yet met with him.

My perch had a clear view down the woodpaneled hallway lined by mathematics faculty offices. Suddenly the familiar, animated voice of Donald Spencer rang down the corridor. Shortly, he came into view, walking rapidly beside a tall, good-looking man who was casually dressed in a sports jacket, without a tie, and carrying a large,

\footnotetext{
Arthur Jaffe is the Landon T. Clay Professor of Mathematics and Theoretical Science at Harvard University. He studied chemistry as a Princeton undergraduate, mathematics at Cambridge University, and later received his doctorate in physics with Arthur Wightman, submitting his thesis in 1965 titled "Dynamics of a cut-off $\lambda \phi^{4}$ field theory". He served as AMS president in 1997-98. His email address is arthur_jaffe@harvard.edu.
} 
well-worn brown leather briefcase brimming with papers. The pair stopped in the hallway, not far from where I sat. Both men were compulsive talkers; they seemed completely engaged in their conversation, unaware that they were being observed.

Arthur Wightman appeared pleasant and even approachable, but formidable nonetheless. Spencer began to tell Wightman about a newly arrived student who planned to study mathematical physics, a student who sounded exactly like me. How extremely awkward to be the subject of a conversation you unintentionally overhear! Coming from an academic family, my father had often explained to me that professors have a human side too, which helped me understand that I had been derelict in my duty by not seeking out Arthur Wightman as soon as I arrived in Princeton. I soon did.

Eventually I became quite familiar with that omnipresent briefcase, with Arthur Wightman's modest Volkswagen Bug, and with Anna Greta's Mercedes. Two years later, at the IHES, someone coined the names "Big Arthur" and "Little Arthur" to distinguish us in conversation. Those adjectives not only described our relative ages and physiques, but also the way I felt at that moment in Fine Hall when I tried to disappear inconspicuously into the woodwork.

\section{Chiara R. Nappi}

I met Arthur in 1973 when I attended a summer school in constructive field theory that he organized at the Ettore Majorana Center in Erice, Sicily (Italy). I remember him sitting through all the lectures, many by his students and collaborators, very attentive and engaged. Arthur was an impressive guy, both intellectually and physically. He was tall and strong (Strong was his middle name).

He had attended Yale on an academic scholarship but had ended up playing basketball for Yale, something he was very proud of, although he readily acknowledged that the decisive element had been his size rather than his athletic skills. He and his wife, Anna-Greta, were quite a sight together. They went bird-watching through Sicily during the free weekend at the school. That was the first time I heard of bird-watching, and I was intrigued. When I arrived in Princeton in 1980, it was Arthur and his second wife, Ludmilla (by then Anna-Greta had lost her battle with cancer), who introduced me to birding.

Arthur was very proud of his association with both the math and physics departments at

Chiara R. Nappi is a professor of physics at Princeton University. She and Arthur had been friends and colleagues for nearly four decades. Her email address is cnappi@ princeton.edu

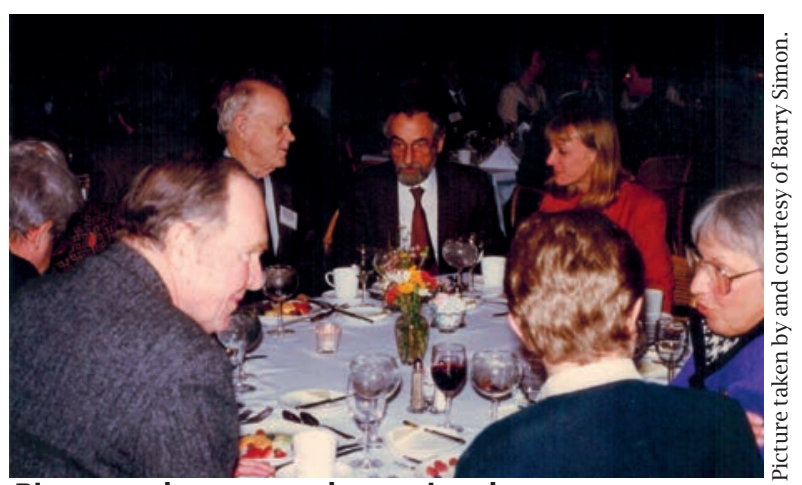

Picture taken at mathematics department dinner in mid-1990s. Ludmilla Wightman is across from Arthur and from I to $r$ are Lars Gårding, Elliott Lieb, and Christiane Fellbaum Lieb.

Princeton University and divided his loyalty evenly between them. One could always find him either in his office in Jadwin (physics department) or Fine Hall (math department). Nonetheless, he liked to joke that one of the advantages of being in two departments was like having both a wife and a lover. The wife thinks you are with the lover, the lover thinks you are with the wife, and you can hide somewhere and get some work done.

If you asked Arthur a question, he would say, "Do you have a minute?" To Arthur there was no such a thing as a quick answer. He knew so much, he had so much to say, so many details to reveal, so many connections to make. You sat there listening to all these facts that he remembered in exquisite detail, totally fascinated. Hours later you finally had the answer to the question you asked long ago, and in the process you had learned an awful lot about a lot of things you did not even know existed and enjoyed every moment of it.

Arthur's office was across the hall from mine. The walls were completely covered with books, and he had read them all. If you asked him where to find something, he would immediately pull out the right book and point you to the right page. Then there were the light blue notebooks, dozens of them, clearly labeled and filled with his neat handwriting. When the office was emptied a couple of years ago, it felt like the end of an era.

By then Arthur had already spent a few years in nursing homes. When his mind started failing him, he built an alternate reality around himself and continued to live in the world he loved. When I would go to visit him, he would ask, "Are you coming straight from your office? With all the construction going on, lately I have not been able to find the elevator from Fine Hall to Jadwin." Or he would say, "Princeton certainly is not what it used to be. Can you believe that there are people here who do not know who Dyson is?" But he never forgot things of the past. Even when he could not recognize the colleagues who visited him, 


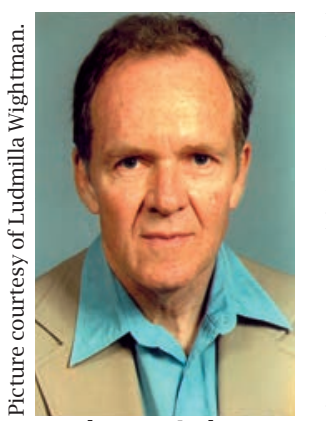

he nonetheless was extremely gracious and friendly, regaling them with memories of physics at Princeton decades earlier. He would say, "I know I should remember you, but I do not... I see I have a lot of remembering to do." Always good-humored, always dignified. A true giant, a great role model, and a gentleman to the very end.

\section{Edward Nelson}

I arrived in Princeton with a background in probability theory and functional analysis but not knowing a Hamiltonian from a Lagrangian. I was fascinated by Feynman's articles on path integrals and wanted to understand his application of them to quantum electrodynamics, so I attended Arthur Wightman's course on QED. But most of what I learned from Arthur was outside the classroom. For years he taught me physics by answering my questions with unfailing generosity and expertise.

Once, I was writing a paper in which I compared classical motion, as described in Whittaker's Analytical Dynamics, with quantum motion for a particle in a $1 / r^{2}$ potential. In both cases there was a division: for angular momentum higher than a certain critical value, the motion was regular, and below the critical value, singular. But the critical values I obtained for the two cases differed by a factor of 2, which puzzled me greatly. I asked a well-known physicist about this. He gave me a lecture about the difference between classical and quantum mechanics, but with no mention of a factor of 2 and, unless I was paranoid, with an implicit suggestion that these matters were beyond the comprehension of a mere mathematician. Then I did what I should have done in the first place: I asked Arthur, telling him just what I have written above. He replied immediately, "Whittaker uses forces rather than potentials." (While a $1 / r$ potential gives an attractive $1 / r^{2}$ force, a $1 / r^{2}$ potential gives an attractive $2 / r^{3}$ force, and there was my missing factor of 2.) This answer was typical of Arthur's encyclopedic knowledge of the literature and his ready grasp of the essentials of a problem. But in another way the answer was quite untypical of him. In fact, it was unique in my experience and perhaps in the experience of everyone who knew him. The answer consisted of a single sentence!

Arthur was famous for his method of answering technical questions, with an impromptu but polished lecture that answered the question only

Edward Nelson was professor emeritus of mathematics at Princeton University. He and Wightman were colleagues on the Princeton faculty beginning in 1959. after putting it in its scientific context, often revealing connections previously unknown to the questioner. Both Chiara Nappi and I expatiate on this at length in our articles on the Princeton physics department webpage www.princeton.edu/ physics/arthur-wightman/, in memory of Arthur.

I am one of many who owe an immense debt of gratitude to Arthur for his enthusiastic, generous, and expert mentoring. This was not simply goodnatured encouragement; it was informed by Arthur's clear vision of where mathematical physics should go and his uncompromising requirement of rigor. When I worked on stochastic mechanics, an unorthodox approach to quantum theory, not a word of encouragement came from Arthur. But he was not one of those scientists who attempt to suppress research directions of which they do not approve. I submitted a book on stochastic mechanics to the Princeton Series in Physics, of which he was one of the editors. After a long delay I asked Arthur what the situation was. He said he had no objection, but that I had better go talk with the other editor, which I did.

Arthur loved mathematical physics. He loved life, he loved people, he loved conversation. A man of great seriousness of purpose, he exuded fun.

\section{David Ruelle}

Wightman Field Theory is the scientific field where I started to do independent work (that was in Zurich, with Res Jost, in 1959). I had met Arthur Strong Wightman himself at physics summer schools and felt that his middle name was singularly appropriate. His vast knowledge of physics and mathematics had allowed him to choose in masterly fashion the axioms on which he based relativistic quantum field theory, and then he developed this Axiomatic or Wightman Field Theory in a beautiful way. He presented his ideas with force and clarity in articles, lectures, and a foundational set of notes (Bargman, Wightman, and Wigner), which unfortunately was left unfinished and seems now to be quite forgotten. One result which astounded me when I studied it was the fantastic calculation of the domain of holomorphy for the 3-point function, which he did with Gunnar Källén. For me these were the golden days, and thinking about them leaves me somewhat nostalgic. Arthur Wightman was the god of the part of science in which I worked, which was a paradise with a number of brilliant people: the Feldverein

David Ruelle is an honorary professor at the Institut des Hautes Etudes Scientifiques (Bures-sur-Yvette) and a visiting professor at the Rutgers Math department. He has known Arthur Wightman since the late 1950s. His email address is rue11e@ihes.fr. 
(Lehmann, Symanzik, Zimmermann), Jost, Haag, and many more. After a while I left the paradise, because I wanted something more constructive than axiomatic field theory, and started working in equilibrium statistical mechanics. But the interests of Arthur Wightman were vast, and I stayed in close scientific contact with him.

At a personal level, the image that comes to mind when I think of him is of Arthur Wightman at his home in Princeton among his books. Because of his role at the Princeton University Press, he had a vast number of books, knew them, and talked about them. His talk about books and other topics could, at times, be a bit overpowering. But listening to him could be quite rewarding. I remember for instance how he described the careful way in which J. Robert Oppenheimer expressed himself: writing down precisely what Oppie said, you had a text already fit to print.

Arthur Wightman was one of the founding fathers of modern mathematical physics at a time when there were only a few dozen people in this domain. His influence was strong, and science today keeps the mark of his great mind.

\section{Barry Simon}

Because of a wonderful high school physics teacher, I wound up as a physics major at Harvard, although I took lots of advanced math courses there. I realized early on that what I really wanted was to prove theorems about real physics. With Wally Gilbert, Paul Martin, and Julian Schwinger as my theoretical physics professors, I didn't see any of that at Harvard, so I cornered George Mackey in the middle of my junior year and asked if he knew anyone doing that sort of thing, and he told me about Arthur Wightman at Princeton. Princeton hadn't been on my radar, but I applied and went to graduate school there and, with Arthur and Ed Nelson as mentors, got a superb education.

When Arthur was starting out, he didn't have anyone like him! He went to Princeton intending to work with Wigner, who was at Oak Ridge, so Arthur did a more phenomenological thesis with Wheeler. His last year Wigner returned and Arthur set aside an hour a week to meet with him. As Arthur told me, "Sometimes we'd discuss my thesis, sometimes a point of physics or mathematics. But if need be, we'd discuss the weather, because darn it, he owed me that hour!"

Arthur told me this in the context of apologizing for going on leave to Europe during my second year, although he was conscientious about writing me long letters with useful advice. I remember one that suggested I use Padé summation on the divergent anharmonic oscillator perturbation series that began: "The specter of Padé is haunting Europe. S-matricists of the world unite. You have nothing to lose...."

The anecdote about Wigner illustrates Wightman's strong sense of right and wrong (in graduate school my friends and I used to joke that there was a reason his middle name was Strong). This carried over to his science. He used

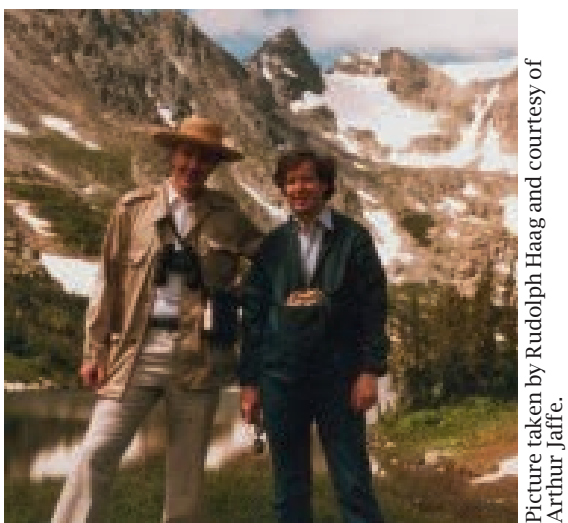

Wightman and Arthur Jaffe at the Boulder meeting of the IAMP, 1983. to complain to me about physicists who claimed there was no need for proofs from first principles because accurate prediction was a proof the arguments were correct. The phrases "intellectual coherence" and "intellectual honesty" were part of his response.

Combined with his sense of right and wrong was a phenomenal breadth of interest and knowledge (someone once remarked that the only thing more intimidating than the number of books in Arthur's office was that he knew what was in all of them) and an incredible generosity. The result was that ideas and research problems that most people would save for themselves were offered to students and postdocs, often not even resulting in joint publication.

One example of this involves dimensional renormalization of Feynman integrals. Arthur learned from Marcel Riesz the idea that one could understand the principal value integral by making the power one a complex variable, note there is a pole at $s=1$ in the analytic continuation, and view the principle value as the constant term in the Laurent series. Arthur had the idea that perhaps one could understand renormalization of Feynman integrals in the same way. He gave a simple low-order example to an undergrad for a senior thesis and then the full idea to Gene Speer as a $\mathrm{PhD}$ thesis problem. In Gene's hands it turned into dimensional renormalization, since a standard tool in both mathematical physics and theoretical physics. I could give many other examples of this sort.

Arthur Wightman was a giant figure who considerably impacted the field of mathematical physics in many ways. He was a wise and caring human being. I am fortunate to be among the many whose lives he changed. 


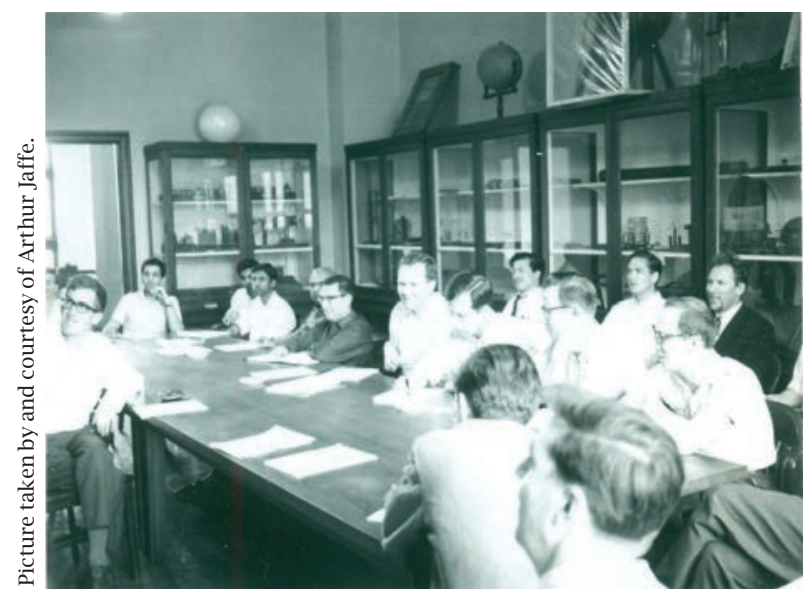

Wightman at his seminar in 301 Palmer Lab, 1965. The picture includes Gerhard Mack, Christian Gruber, Henri Epstein, Wightman, Rein Uritam, Rudolph Hwa, Anton Z. Capri, Dietrich Uhlenbrock, George Svetlichny, Jean Nuyts, Marcel Froissart, and several others.

\section{Ray Streater}

When I visited Princeton in 1963 to work with Wightman on a book, I shared his office. I noticed that he tutored students there, and I used to leave him when they arrived. One student, a young black man, was a particularly frequent visitor. Wightman treated him very kindly when he arrived, and his help went well beyond the physics. I realized after I returned to England in 1964 that segregation was still a problem in the USA: the huge demonstration against it, which took place in the summer of 1964, was indeed necessary.

\section{Franco Strocchi}

I met Arthur Wightman in the early sixties. During a one-semester visit to the physics department of Iowa State University, Fritz Rohrlich introduced me to the problem of a gauge independent formulation of quantum electrodynamics (QED), possibly improving Mandelstam's proposal. When back in

Ray Streater is a retired professor of mathematics at King's College London. He visited Wightman at Princeton University for six months, 1962-63, to help write up the account he had started of what is now known as "Wightman theory." It appeared in 1964 as a book entitled PCT, Spin and Statistics, and All That. His email address is raystreater@gmai 1.com.

Franco Strocchi is a retired professor of theoretical physics. On invitations by Wightman, he was in Princeton in the seventies and early eighties as research associate and as visiting professor. His email address is f.strocchi@ sns.it.
Europe, I chose to spend a postdoctoral fellowship at Orsay, where Maurice Lévy had also worked on the same problem. In the process of finishing the paper with Rohrlich, I was struck by the fundamental paper by Wightman and Gårding on the mathematical formulation of quantum field theory, containing in particular a very neat section on the quantization of the electromagnetic potential. I then decided to spend my second year of fellowship at Princeton, where I arrived in January 1966. A new world was disclosed to me, and, in particular, I experienced the extraordinarily distinctive ability of Wightman to encourage and promote research work, according to his scientific style.

I went back to Princeton in the years 1972-73 with the aim of discussing with Wightman the implications of the Gauss law on the algebra of observables on the basis of a preprint with Ferrari and Picasso, which appeared only in 1974. The mathematical problem was the relation between the quantum number of the electric charge and the integral of the charge density: in the physical Coulomb gauge such a connection was plagued by the infinite renormalization constants due to vacuum polarization, as pointed out by Symanzik in his unpublished lectures of 1971. On the other hand, the Feynman-Gupta-Bleuler gauge offered a possible framework. Wightman reacted very favorably to this possibility and actually suggested an extensive control of the mathematical structure of that gauge. The result was a joint paper on the charge superselection rule and a proposal to write a book on what could be said on QED from a mathematical point of view.

We started exchanging letters and drafts. I still have a copy of Chapter I on classical electrodynamics and part of Chapter II on the Fock representation of the vector potential in a Krein-Hilbert space, both written by Wightman. We kept dreaming of our joint project during my visits to Princeton in 1976-77, 1980-81, and of Wightman to Pisa in 1993, but the project was slowly fading away. One of the reasons was that the subject was still in evolution, and it took time to fix some of the relevant issues. In fact, such a project turned out to be an endless source of interesting problems, such as the control of chiral symmetry breaking in the local quantization $\mathrm{QED}_{1+1}$, with a mathematical analysis of the local quantization of the massless scalar field in two dimensions; the failure of the cluster property in local gauges; the nonregular representations of the field algebra defined by gauge invariant vacuum states; the construction and properties of the charged states; the proof of the charge superselection rule in the Coulomb gauge, the nonperturbative discussion of the Higgs mechanism; etc.

The influence of Wightman on my work has been so strong that I could hardly imagine what it would have been without him. 


\section{Giorgio Velo}

I became acquainted with Arthur Wightman at the beginning of 1964 when Arthur, on sabbatical in Europe, paid a short visit to Res Jost, then a professor at the ETH in Zurich. At that time I was passing a few months at the ETH in Zurich with an Italian fellowship to familiarize myself with rigorous quantum field theory. During the summer Arthur and I met again at the Cargese, Corsica (France) Summer School in Theoretical Physics. Arthur lectured extensively on two-dimensional solvable models in quantum field theory and stimulated my interest in the subject. As a speaker his style was simple and lucid. I started to understand why, besides being a leading scientist, he was also considered a gifted teacher.

In November of the same year I was in Princeton for one year--supported by a NATO fellowship, hosted by Arthur in his group. Arthur had a large number of students, postdocs, and others working on rigorous quantum theory under his leadership. He was generous in sharing his knowledge and experience with all of them and actually devoted an enormous amount of time to discussions. In connection with his Cargese lectures he suggested to me the problem of writing a rigorous solution of the two-dimensional Schwinger model. During that research I always received from Arthur both warm encouragement and help in order to overcome the technical difficulties. That year was crucial for my scientific growth. In Princeton I lived in an exciting atmosphere, and I had the strong impression of important scientific events taking place. I met colleagues and made friends for life: John Challifour, John Dollard, Marcel Guenin, Arthur Jaffe, Oscar Lanford, and others. During that year Arthur taught a course on quantum field theory for which I still have the notes. It was a remarkably wide presentation of various aspects of that discipline so inspiring that, as an immediate fallout, Klaus Hepp, who was in the audience, wrote an important paper on renormalization theory.

In subsequent years Arthur and I became independently interested in the theory of relativistically invariant wave equations, with particular attention to equations describing higher spin particles. We corresponded frequently on that subject. While I was working on specific examples, Arthur devoted himself mostly to general theory writing, thorough papers containing many suggestions for future developments.

Giorgio Velo was professor of mathematical methods for physics at the University of Bologna (Italy). Arthur Wightman and Giorgio Velo were co-directors of the International School of Mathematical Physics of the Ettore Majorana Center for Scientific Culture located in Erice, Sicily, Italy. His email address is Giorgio.Velo@bo. infn. it.

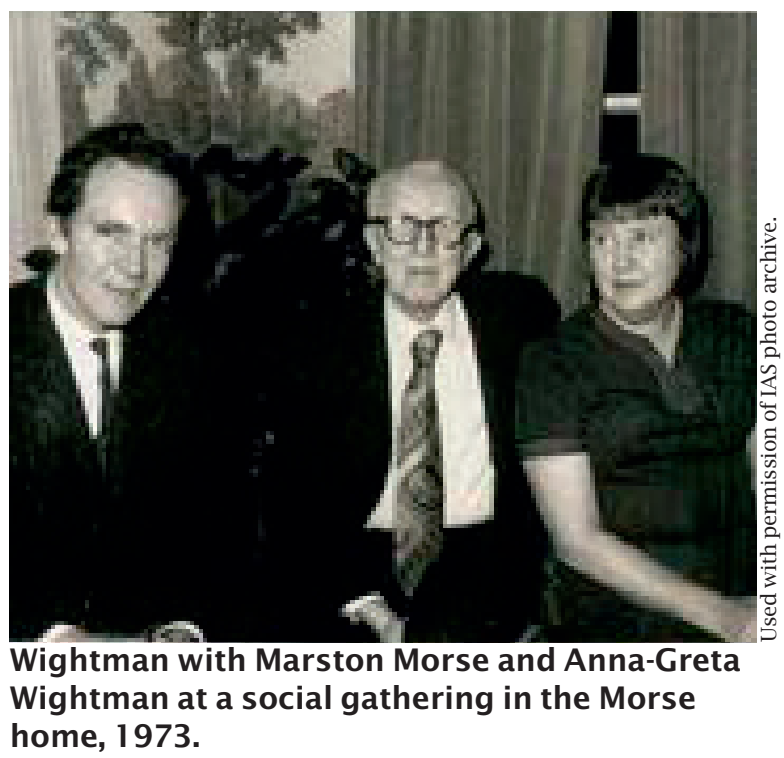

Starting in 1973, within the Ettore Majorana Center for Scientific Culture, located in Erice, Sicily (Italy), Arthur and I organized seven summer courses on various topics of mathematical physics: Constructive quantum field theory (1973), Renormalization theory (1975), Invariant wave equations (1977), Rigorous atomic and molecular physics (1980), Regular and chaotic motions in dynamical systems (1983), Fundamental problems of gauge field theory (1985), Constructive quantum field theory II (1988). They resulted in seven volumes of invited lectures, published variously by Springer, Reidel, and Plenum. I remember quite well Arthur's enthusiasm about this pedagogical activity.

The scientific community sorely misses a scholar and a gentleman, and I miss a true friend. 